\title{
VARIABILITY IN PAVEMENT DESIGN
}

Paola Dalla Valle

Senior Engineer, Arup, The Arup Campus, Blythe Valley Park, Solihull, B90 8AE, United Kingdom. Email: paola.dallavalle@arup.com

Dr Nick Thom

Lecturer, Department of Civil Engineering, Nottingham Centre for Pavement Engineering, University of Nottingham, NG7 2RD, United Kingdom. Email: nicholas.thom@nottingham.ac.uk

doi: 10.1515/ijpeat-2015-0009

\section{ABSTRACT}

This paper presents the results of a review on variability of key pavement design input variables (asphalt modulus and thickness, subgrade modulus) and assesses effects on pavement performance (fatigue and deformation life). Variability is described by statistical terms such as mean and standard deviation and by its probability density distribution.

The subject of reliability in pavement design has pushed many highway organisations around the world to review their design methodologies, mainly empirical, to move towards mechanistic-empirical analysis and design which provide the tools for the designer to evaluate the effect of variations in materials on pavement performance. This research has reinforced this need for understanding how the variability of design parameters affects the pavement performance.

This study has only considered flexible pavements. The sites considered for the analysis, all in the UK (including Northern Ireland), were mainly motorways or major trunk roads. Pavement survey data analysed were for Lane 1, the most heavily trafficked lane. Sections $1 \mathrm{~km}$ long were considered wherever possible.

Statistical characterisation of the variation of layer thickness, asphalt stiffness and subgrade stiffness is addressed. A sensitivity analysis is then carried out to assess which parameter(s) have the greater influence on the pavement life.

The research shows that, combining the effect of all the parameters considered, the maximum range of 15 th and 85 th percentiles (as percentages of the mean) was found to be $64 \%$ to $558 \%$ for the fatigue life and $94 \%$ to $808 \%$ for the deformation life.

\section{INTRODUCTION}

Achieving durability of pavement structures is crucial not only for the Highways England (formerly the Highways Agency) in the UK but for any other highway authority in the world. Funding is getting tighter for both new build and maintenance of existing assets with consequent pressure on highway designers to construct durable pavements which offer at the same time good value for money to the client, minimum disruption to road users, and minimal impact on the environment. 
However, it is difficult to accurately design and predict the life and form of distress of a pavement structure because all of the variables involved, such as traffic prediction, material properties and layer thickness, are random/uncertain/stochastic in nature. This means that these variables vary in space and time with resulting variability in the performance of a pavement.

Most pavement engineers know that pavement materials, environment, loading and construction affect the performance of a pavement and the variability observed in each of these parameters introduces a certain level of risk. The recognised need to account for these variabilities in the design process is pushing many highway authorities in the world to move from a traditional deterministic approach, based on a single input/output value, towards a probabilistic design, which includes a mean, variance and probability distribution. The probabilistic approach offers a way of incorporating risk assessment considerations which are vital for whole-life cycle economic analysis and decisions.

Consequently, variability of the pavement design input parameters and appropriate methods to account for this variability to estimate correctly the probability of failure have to be considered and developed. Accurate and reliable pavement performance predictions during a pavement's design life are of vital importance to minimise the risk of premature failure.

This paper presents the results of a research study on the variability of the most important factors involved in the pavement design, namely the layer thickness, asphalt stiffness and subgrade stiffness. Of course it is acknowledged that many other factors (notably fatigue resistance) affect pavement life in reality; however, stiffness modulus and layer thickness are the variables generally considered in analytical pavement design.

Variability is described by statistical terms such as mean and standard deviation and by its probability density distribution. A sensitivity analysis is then carried out to assess which parameter(s) have the greater influence on the pavement life (fatigue and deformation life).

The scope of the study is to consider flexible pavements only and to consider thickness data from non-destructive radar surveys. The sites considered for the analysis, all in the UK (including Northern Ireland), are mainly motorways or major trunk roads. The focus of the analysis remains on Lane 1, the most heavily trafficked lane, and sections $1 \mathrm{~km}$ long were considered wherever possible. A total of eight sites were considered in the research.

\section{Parameters affecting pavement performance}

The main parameters affecting pavement performance can be grouped as follows (see Figure 1):

- The properties of the subgrade soil on which the pavement layers will be constructed. This parameter is generally represented by the subgrade stiffness.

- The pavement layer characteristics represented by the layer thicknesses and stiffnesses. 
- The traffic characteristics that the pavement will withstand during the design period. This parameter is generally represented by the accumulated number of ESALs (Equivalent Standard Axle Loads).

- The climatic conditions that the pavement will be subjected to during the design period.

- The quality of construction methods and workmanship.

- The timing and appropriate schedule of maintenance treatments.

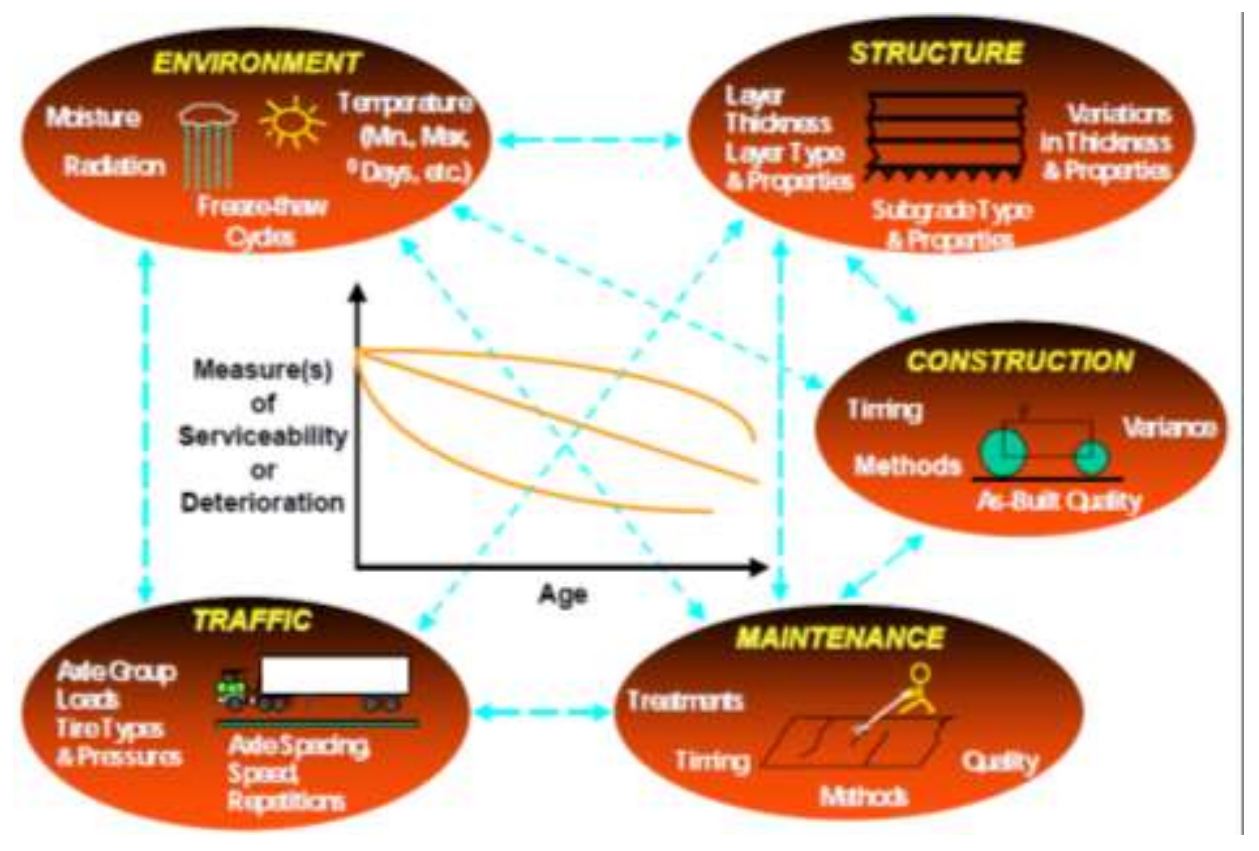

Figure 1. Factors influencing pavement performance (from Tighe et al., 2001)

While construction and maintenance activities clearly affect the pavement performance, these factors cannot be directly accounted for in the design process. Much emphasis is, therefore, given to the other parameters used in the design; namely traffic, the environmental conditions, and structure and materials.

\section{Pavement design approaches and performance prediction models}

The major components of pavement design are the input system, prediction models, transfer functions and an output system that consists of predicted pavement performance. Current pavement design approaches (Jiménez and Mrawira, 2012) can be divided into two categories: deterministic and probabilistic. In a deterministic approach single values are adopted for all input parameters and the prediction results are single numbers of pavement performance. In contrast, probabilistic analysis treats all input parameters as variables that change according to an assigned probability distribution function. Probabilistic analysis also yields a more comprehensive estimate than deterministic analysis by providing a range of likely outputs.

Performance prediction modelling is an important element in decision making tools such as Pavement Management Systems, Asset Management systems and design systems. Available prediction models are generally simplified and specific to local conditions. 
Performance prediction models can be divided into:

- Mechanistic

- Empirical (such as the 1993 AASHTO guide, and semi-empirical such as the UK pavement design described in HD 26, DMRB Vol 7)

- Mechanistic - Empirical (such as the 2008 M-E Design Guide, AASHTO)

In the current UK standards reliability is implicitly embraced in the response model such that a pavement has an $85 \%$ probability of achieving the design life.

\section{Definition of failure}

A pavement is designed to withstand the design traffic during its design life. A pavement failure is characterised by the development of a particular type of distress (such as fatigue cracking and rutting on flexible pavements) of sufficient severity and extent at different points within a pavement section. Despite a pavement section being designed and constructed the same way, random variations in material properties and as-built characteristics cause localised deficiencies.

\section{Stress calculation}

A number of different analytical models can be used to predict the stress, strain and deformation in a pavement under simulated wheel and environmental loading conditions. The main models are based on multilayer elastic theory and Finite Element analysis.

In this research, Odemark's Method of Equivalent Thicknesses (MET) (Ullidtz, 1987) and Shell's specialist software "BISAR" were used to calculate the stresses and strains for various pavement structures.

\section{Transfer functions}

Transfer functions are relationships developed to relate the state of stress in a pavement to its overall performance. In current M-E design procedures for flexible pavements - despite the multitude of relationships available - the primary transfer functions are those that relate 1) wheel load tensile strain at the bottom of the asphalt layers to eventual fatigue cracking and 2) wheel load compressive strain (or stress) at the top of the subgrade to permanent deformation.

The performance prediction models used in the UK and adopted in this paper are (Powell et al., 1984):

- Structural cracking: the number of traffic loads to fatigue failure $\left(N_{f}\right)$ of asphalt layers is determined on the basis of horizontal tensile strain at the bottom of the asphalt layer $\left(\varepsilon_{r}\right)$ :

$\log N_{f}=-9.38-4.16 \times \log \varepsilon_{r}$

- Structural deformation: the number of traffic loads to deformation (rutting) failure $\left(N_{d}\right)$ is determined on the basis of vertical compressive strain at the top of the subgrade $\left(\varepsilon_{z}\right)$ :

$$
\log N_{d}=-7.21-3.95 \times \log \varepsilon_{z}
$$




\section{PERFORMANCE OF PAVEMENT DESIGNS}

All variations in materials and construction, if not properly incorporated into the design procedure, may contribute to premature failure of a pavement structure. In addition, the design equations are often based on observations of the performance of sections of roads built in the past where different material properties and construction techniques were employed compared to those of today. This issue probably justifies the large difference sometimes observed between the performance life and the intended design life.

These considerations are expressed in Figure 2. For example, although a pavement is designed for a 20 year design period, with reconstruction or rehabilitation expected at the end of the design life, the actual pavement may exhibit sections that fail prematurely.

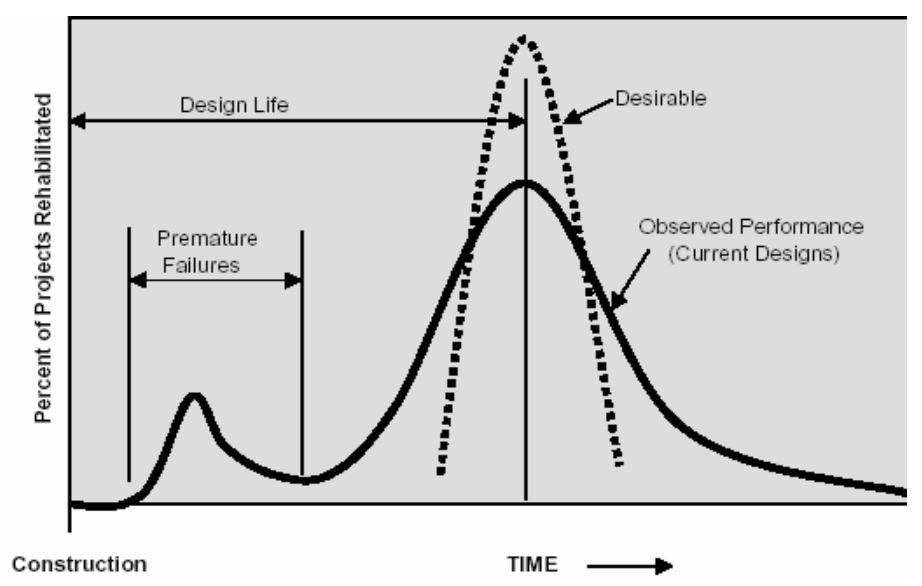

Figure 2. Performance of existing pavement designs (from Transportation Research Circular E-C118, 2007)

If the material variability were known and included in the design procedure the difference between the design and in-service life should be reduced. This knowledge would also allow better and more robust decisions to be taken in terms of whole life cost analysis. Material variability can be described by statistical terms such as mean and standard deviation together with its probability density distribution. A useful dimensionless way of expressing the variability of a material's property is to use the ratio of the standard deviation over the mean, known as coefficient of variation $(\mathrm{COV})$. Knowledge of the coefficient of variation of each design input is extremely important to more accurately estimate their influence on the predicted pavement life.

\section{Impact of variability on pavement performance}

Many pavement design procedures are based around single values of the pavement and traffic characteristics which represent average conditions - average values, sometimes with a margin of safety, that do not account for variability in the pavement and traffic loads. Variability exists in pavements due to construction practices, quality control, environmental conditions, material characteristics and traffic conditions and this variability has been known for quite a while (Darter et al., 1973). 
The variability associated with traffic and pavement parameters has a significant impact on the performance of pavements (and reliability of pavement design) and should, therefore, be addressed and quantified when modelling pavement performance and when developing maintenance programmes. Therefore, the major design input parameters for pavement design such as moduli of layers, thickness of layers, traffic volume etc. should each be defined as a random variable with its mean and standard deviation (assuming a normal distribution) or its complete probability distribution. The pavement performance function can subsequently also be characterised in statistical terms. In other words, because the values used to calculate the performance life of a pavement structure (e.g. fatigue life $\mathrm{N}_{\mathrm{f}}$ ) are not exact values but are distributed over a range, for each pavement there is an expected value of $\mathrm{N}_{\mathrm{f}}$ and associated variance that describes the distribution $\mathrm{N}_{\mathrm{f}}$ will follow. George and Husain (1986) and later Prozzi and Guo (2007) have supported previous significant experimental evidence that the distribution of fatigue lives at a particular stress level is lognormal.

Quantifying and analysing variability of pavement materials and design inputs are, therefore, fundamental in developing a probabilistic-based design that evaluates reliability. Kim et al. (2003) grouped the main sources of uncertainty in the AASHTO M-E flexible pavement design into two categories:

- Uncertainties of design parameters; and

- Systematic errors

The first group represents the spatial variability and inconsistent estimation of the parameters (e.g. random measurement error in determining the strength of subgrade soil) while the second group is related to the model bias in predicting pavement performance.

\section{Summary of variability of design input parameters}

A summary of the variability of design input parameters from published sources - for the Mechanistic-Empirical pavement design approach - is depicted in Table 1. The key results from the studies referred to in Table 1 are summarised as follows:

- The most influential design inputs on reliability were layer properties and thickness, followed by traffic and lack-of-fit error.

- The parameters with the greatest influence on the variability of predicted fatigue performance, without considering variable loads, were asphalt modulus and thickness.

- Fatigue cracking was affected by changes in the asphalt layer thickness while it was unaffected by changes in the granular base layer thickness.

- The parameters with the greatest influence on the variability of predicted deformation (rutting) performance, without considering variable loads, were the granular base thickness, asphalt thickness, and stiffness of the subgrade.

If the traffic axle weight variability was added the output variability for fatigue and deformation performance was significantly changed (i.e., more than doubled). 
Table 1. Summary of pavement material COVs from available literature (for the Mechanistic-Empirical pavement design approach)

\begin{tabular}{|c|c|c|c|c|c|}
\hline \multirow[t]{2}{*}{ Property } & \multirow[t]{2}{*}{ Description } & \multicolumn{4}{|c|}{ Previous Investigation } \\
\hline & & $\begin{array}{l}\text { Range of } \\
\operatorname{COV}(\%)\end{array}$ & $\begin{array}{l}\text { Typical } \\
\operatorname{COV}(\%)\end{array}$ & $\begin{array}{l}\text { Type of } \\
\text { distribution }\end{array}$ & Reference \\
\hline \multirow[t]{8}{*}{$\begin{array}{l}\text { Layer } \\
\text { Thickness }\end{array}$} & \multirow[t]{2}{*}{$\begin{array}{l}\text { Bituminous } \\
\text { surface }\end{array}$} & $3-12$ & 7 & Normal & $\begin{array}{l}\text { Timm et al. } \\
(2000) \text {, Noureldin } \\
\text { et al. (1994) }\end{array}$ \\
\hline & & $3.2-18.4$ & 7.2 & Normal & $\begin{array}{l}\text { Aguiar-Moya et al. } \\
(2009)\end{array}$ \\
\hline & \multirow[t]{2}{*}{$\begin{array}{l}\text { Bituminous } \\
\text { binder course }\end{array}$} & $\begin{array}{l}11.7- \\
16.0 \\
\end{array}$ & 13.8 & Normal & $\begin{array}{l}\text { Aguiar-Moya et al. } \\
(2009)\end{array}$ \\
\hline & & $5-15$ & 10 & Normal & Noureldin et al. (1994) \\
\hline & \multirow{2}{*}{ Granular base } & $10-15$ & 12 & Normal & Noureldin et al. (1994) \\
\hline & & $6.0-17.2$ & 10.3 & Normal & Noureldin et al. (1994) \\
\hline & $\begin{array}{l}\text { Granular } \\
\text { subbase }\end{array}$ & $10-20$ & 15 & Normal & Noureldin et al. (1994) \\
\hline & $\begin{array}{l}\text { Overlay } \\
\text { thickness }\end{array}$ & & & Lognormal & Tighe (2001) \\
\hline \multirow{8}{*}{$\begin{array}{l}\text { Elastic } \\
\text { Modulus }\end{array}$} & \multirow{2}{*}{$\begin{array}{l}\text { Bituminous } \\
\text { Layers }\end{array}$} & $10-20$ & 15 & Normal & Noureldin et al. (1994) \\
\hline & & $10-40$ & & Lognormal & Timm et al. (2000) \\
\hline & \multirow[t]{2}{*}{ Granular base } & $10-30$ & 20 & Normal & Noureldin et al. (1994) \\
\hline & & $5-60$ & & Lognormal & Timm et al. (2000) \\
\hline & \multirow{2}{*}{$\begin{array}{l}\begin{array}{l}\text { Granular } \\
\text { subbase }\end{array} \\
\end{array}$} & $10-30$ & 20 & Normal & Noureldin et al. (1994) \\
\hline & & $5-60$ & & Lognormal & Timm et al. (2000) \\
\hline & \multirow[t]{2}{*}{ Subgrade } & $10-30$ & 20 & Normal & Noureldin et al. (1994) \\
\hline & & $20-45$ & & Lognormal & Timm et al. (2000) \\
\hline \multirow[t]{3}{*}{ CBR } & Base & $10-30$ & 20 & Normal & Noureldin et al. (1994) \\
\hline & Subbase & $10-30$ & 20 & Normal & Noureldin et al. (1994) \\
\hline & Subgrade & $10-30$ & 20 & Normal & Noureldin et al. (1994) \\
\hline \multirow[t]{2}{*}{ Traffic } & & - & & $\begin{array}{l}\text { Extreme Value } \\
\text { Type I }\end{array}$ & Timm et al. (2000) \\
\hline & & - & & $\begin{array}{l}\text { Normal, } \\
\text { Lognormal and } \\
\text { Poisson }\end{array}$ & $\begin{array}{l}\text { Zollinger and } \\
\text { McCullough (1994) }\end{array}$ \\
\hline
\end{tabular}

\section{RESEARCH METHODOLOGY}

The sites used in the research were eight in total (M01 to M08) and were mainly motorways (asphalt thickness ranging from $0.260 \mathrm{~m}$ to $0.480 \mathrm{~m}$ ) with two further sites being of a thinner pavement construction (M07 and M08). All sites had a fully flexible construction. The survey data available for these sites were: GPR (Ground Penetrating Radar), cores, FWD (Falling Weight Deflectometer), DCP (Dynamic Cone Penetrometer), IT-CY (Indirect Tension test on CYlindrical specimens, also known and referred to in this paper as the ITSM test, Indirect Tensile Stiffness Modulus) and traffic data. The survey data referred to lane 1, the most heavily trafficked lane. The length of each site varied but, wherever possible, a length of $1 \mathrm{~km}$ was used. Specialist software packages were used, including BISAR (Version 3.0, Shell, UK) for calculation of stresses and strains in the pavement structure and MODULUS-HA (Version 5.1, Highways Agency, UK) for FWD back-analysis. The following sections summarise the results of the statistical characterisation of the main pavement design input variables, namely asphalt modulus and thickness, and subgrade modulus. 


\section{Statistical characterisation of layer thickness variability}

The pavement performance can vary significantly due to the variability in pavement layer thickness, which is mainly due to the construction process and quality control procedures in place. Therefore, even though a unique design thickness is specified for a road section, the actual (as-built) thickness is not constant. The pavement layer thickness is expected to have a certain probability distribution with a higher density around the mean target thickness. Layer thickness information, obtained GPR surveys, has been calibrated by means of cores.

To characterise layer thickness variability for the available sites, the first task was to plot the GPR data and then to group the thickness values into defined interval ranges. For example, a $1 \mathrm{~km}$ section of a motorway (Section A, site M01, Northbound direction) is here shown in Figure 3 to Figure 5. The pavement structure of the M01 motorway consists of $260 \mathrm{~mm}$ of asphalt material $(35 \mathrm{~mm}$ of surface course, $90 \mathrm{~mm}$ of HMB15 binder course and $135 \mathrm{~mm}$ of HMB15 base) on top of $150 \mathrm{~mm}$ of granular sub-base and $350 \mathrm{~mm}$ of capping material. From the GPR survey, continuous values for the foundation are only available for the top layer (i.e., sub-base).

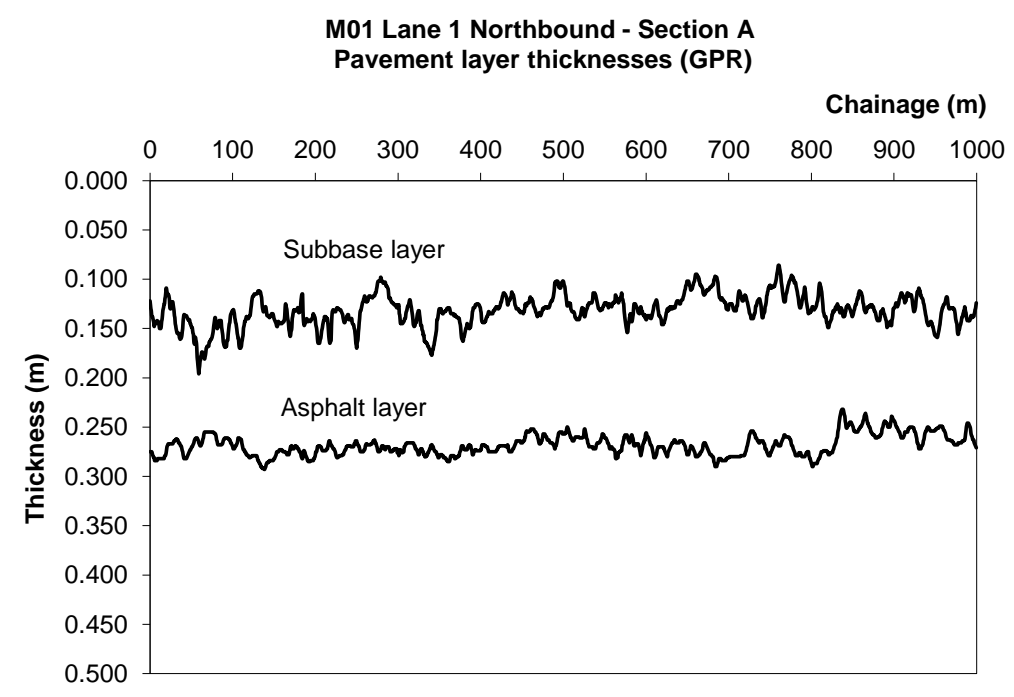

Figure 3. GPR thickness values for total asphalt and sub-base thickness, relating to $1 \mathrm{~km}$ section of site $\mathrm{M01}$

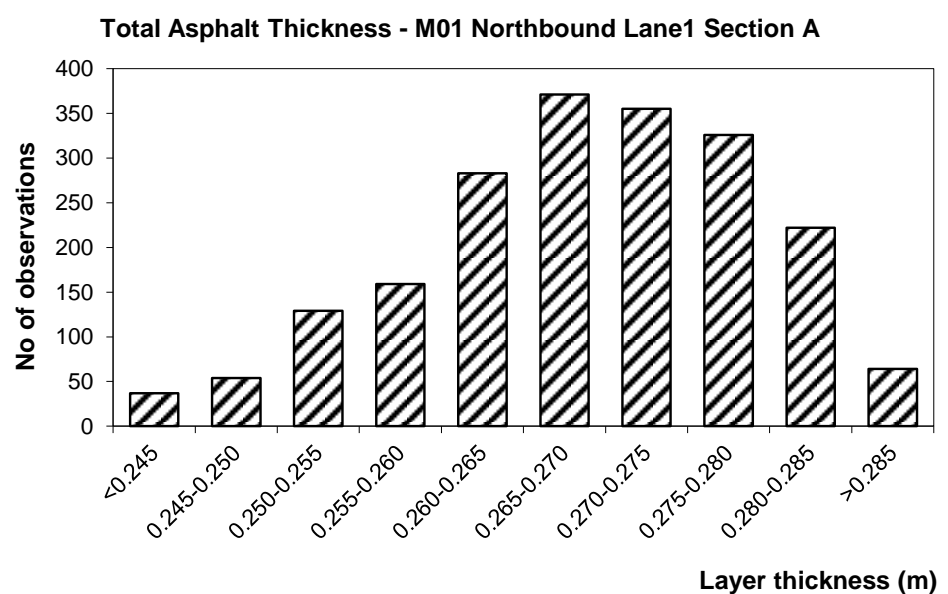

Figure 4. Histogram representation for total asphalt layer thickness distribution, relating to $1 \mathrm{~km}$ section of site M01 


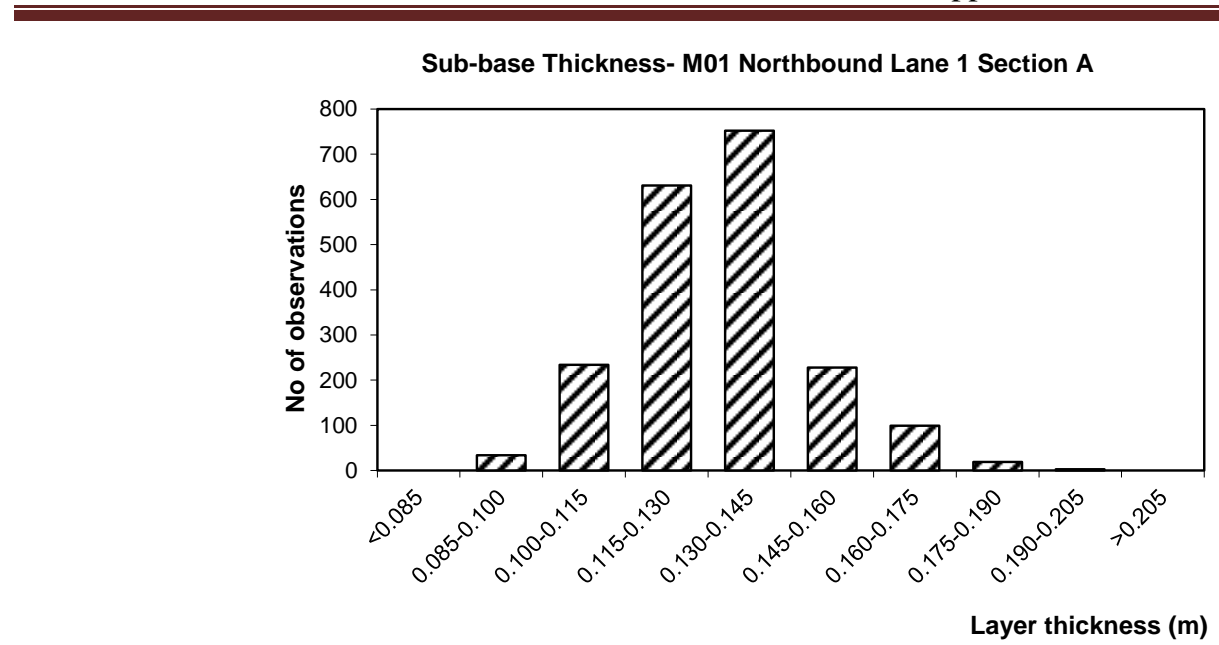

\section{Figure 5. Histogram representation for sub-base layer thickness distribution, relating to $1 \mathrm{~km}$ section of site $\mathrm{M01}$}

From the figures above it can be seen how variable the distribution can be around the design mean thickness of $260 \mathrm{~mm}$ and $150 \mathrm{~mm}$, for the asphalt and sub-base layer respectively.

A basic statistical analysis of the GPR data available on all sites was performed and parameters such as mean thickness, standard deviation, coefficient of variation (COV) and the probability distribution that fits the data best was calculated for the total asphalt pavement layer and for the subbase layer, for each section length.

The results of the research into a statistical characterisation of layer thickness variability showed that:

- The probability distribution for the layer thickness for the UK sites could be considered normal.

- The coefficient of variation is broadly similar to those reported in the American literature (e.g. average 10\% COV for the asphalt layer and 15\% COV for the subbase layer).

- Although some degree of correlation appears to exist between the asphalt and subbase layer thickness for some sections, overall the two thickness profiles can be considered uncorrelated.

\section{Statistical characterisation of asphalt stiffness modulus variability}

The stiffness of asphalt mixtures is of paramount importance in determining how well a pavement performs and is fundamental to the analysis of pavement response to traffic loading. There are various laboratory tests that can be used to assess the stiffness moduli of asphaltic materials, including beam tests and uniaxial compression tests. In the UK, the assessment of asphalt mixture stiffness from in-service pavements is normally carried out by laboratory tests (ITSM tests) and field measurements (FWD surveys) at (or converted to) a temperature of $20^{\circ} \mathrm{C}$, and this is the approach that has been followed here. Temperature variation through the year is not explicitly taken into account.

The research has assessed the effect of three major sources of errors on the backcalculated pavement layer moduli (asphalt layer modulus only) - namely pavement thickness errors, random deflection errors and limited number of data points. Other 
uncertainties, not included in the analysis, are associated with simplifications and assumptions in the backcalculation process and model used for pavement life predictions.

\section{Effect of pavement thickness errors on back-calculated moduli}

In order for the FWD back-analysis to give reliable estimates of the in-situ asphalt stiffness modulus, it is essential to use accurate pavement layer thickness information. Clause 5.28 in HD 29/08 states "For example, a 15 per cent underestimate of the thickness of a bound layer can result in a fifty per cent overestimate of the stiffness of that layer."

Collop (2000) presented a model for statistical correction of asphalt layer stiffness moduli determined from the FWD test to account for asphalt layer thickness variations. Equation (9) and Equation (10) given in Collop (2000) were used to predict the FWD stiffness modulus mean error and the FWD stiffness modulus standard deviation error respectively.

\section{Effect of random deflection errors on back-calculated moduli}

For a pulse-loading deflectometer there are three basic sources of errors in the deflection readings: seating errors, systematic errors and repeatability (or random) errors. Seating errors can be minimised by making at least two drops of the mass before recording test data. Irwin (2009) explains the concepts of systematic and random errors. The systematic error is the difference between the mean measured value of a deflection and the absolute correct deflection value. The random error is the scatter around the mean value.

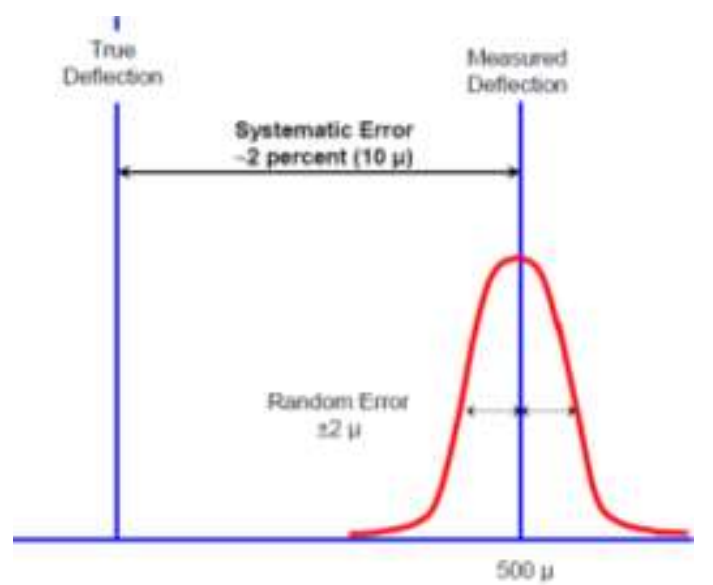

Figure 6. Random and systematic deflection measurements errors (figure taken from Irwin, 2009)

The impact of the repeatability (or random) error on back-calculated layer moduli has been assessed. It was found that the average error due to random measurement deflection error was less than $1 \%$ on back-analysed asphalt stiffness and close to $0 \%$ on back-analysed subgrade stiffness. The effect of random deflection measurement error has been further minimised by making at least three replicate drops at each drop height. 


\section{Effect of limited number of data points on back-calculated moduli}

Collop (2000) determined the confidence limits for back-calculated asphaltic material stiffness modulus from FWD tests using a variable number of measurement points using a normalised mean error and a standard deviation error. His study showed that:

- The accuracy of the mean stiffness modulus estimates depends on the ratio of estimated standard deviation (i.e. value of the stiffness modulus standard deviation using a limited number of data points) to true stiffness modulus (i.e. value of mean stiffness modulus using an infinite number of data points) and the number of samples.

- The accuracy of the standard deviation of the layer stiffness modulus estimates depends on the number of samples.

In the cases covered in this paper, the number of data points was found to be sufficient for such correction not to be necessary.

\section{ITSM tests from available sites}

ITSM tests (on recovered cores) were available for all the sites considered in this research. However, only the ITSM tests performed on motorway M01 were analysed as the number of ITSM tests on the other sites was too low for confident interpretation.

From plotting all the available ITSM tests on the M01 site, see Figure 7, it can be seen that:

- A lognormal probability distribution is found representative of the asphalt layer stiffness modulus.

- The coefficient of variation appears, on average, to range from 20 to $40 \%$, which is in line with the results found by Noureldin et al. (1994) and Timm et al. (2000), see Table 1 .

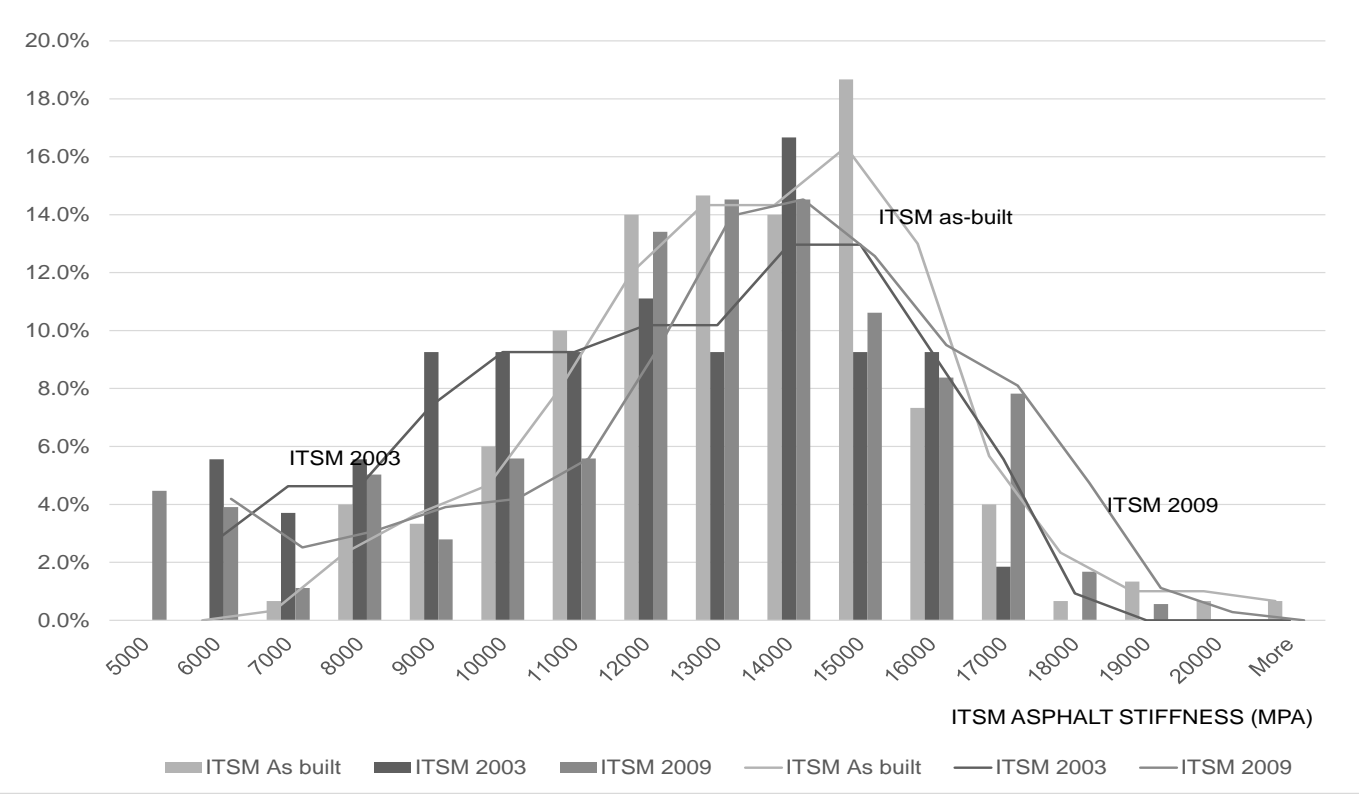

Figure 7. ITSM stiffness data for motorway M01 


\section{Statistical characterisation of subgrade stiffness variability}

Subgrade stiffness is another key input parameter to analytical pavement design. The scope of the design, for example in terms deformation life, is to ensure that there is only limited deformation on the subgrade at the end of the design life due to stresses induced by traffic loads to the subgrade (through the road pavement). Subgrade stiffness affects not only the level of stresses in the subgrade but also the levels of stresses generated in all the overlying pavement layers.

To characterise the spatial variability of the subgrade stiffness for the available UK sites, FWD deflections and back-analysed layer stiffnesses were used. In order to isolate the 'true' subgrade variability from other sources of variability (i.e., variations in layer thickness), a 'cusum' analysis was applied to the FWD central deflection (d1), to the asphalt layer thickness and to the subbase layer thickness (from GPR surveys). Whenever the slope of the cusum plots for either the $\mathrm{d} 1$ deflections or the asphalt layer thickness or the subbase layer thickness changed, a new homogeneous section was considered to begin.

As a result, a high number of homogenous sections were derived from the cusum analysis. Only sections with at least 8-10 points were considered, i.e. approximately $200 \mathrm{~m}$ minimum length. Once the homogeneous sections were identified for each site, a back-analysis was carried out with the asphalt and subbase layer thicknesses derived from the GPR data. For those sections where no GPR subbase thickness was available (i.e. sites M07 and M08), a 300mm layer thickness was used, which is typically expected for a subgrade CBR of $3 \%$.

The back-analysis was carried out with the pavement modelled firstly as a 3-layer structure (i.e., asphalt layer on top of subbase layer and subgrade) and secondly as a 2-layer structure (i.e., asphalt as the top layer and the sub-base combined with the subgrade to form the second layer).

Based on the cusum analysis on the available sites it was observed that:

- The coefficient of variation of the back-analysed subgrade stiffness modulus for all sites varied from a minimum of $8 \%$ to a maximum of $129 \%$, with an average value of $56 \%$. The high uncertainty in the data is probably due to the small sample size derived from the cusum analysis.

- A lognormal probability distribution was found in most cases to be representative of the subgrade stiffness.

\section{Sensitivity analysis}

A sensitivity analysis was carried out at this point on each homogeneous section to assess which parameter(s) have the greater influence on the pavement life. While the focus was on the effect of subgrade stiffness modulus variability on pavement life, variations in asphalt and subbase layer thicknesses and moduli were employed to get a comparative view of the importance of the subgrade.

The basic model was a three-layer pavement structure (asphalt layer with thickness Ta and stiffness Ea, overlying a subbase layer with thickness Tsb and stiffness Esb on top of subgrade with stiffness Esg). The analysis consisted in calculating with BISAR, for 
each homogeneous section, the asphalt and subgrade strains for each of the following cases:

- Base case where all parameters $\left(\mathrm{E}_{\mathrm{a}}, \mathrm{T}_{\mathrm{a}}, \mathrm{E}_{\mathrm{sb}}, \mathrm{T}_{\mathrm{sb}}\right.$, and $\left.\mathrm{E}_{\mathrm{sg}}\right)$ are constant, i.e. with their mean values $(\mu)$;

- The 15th percentile of the parameter of interest is considered, taken from real data, while others are constant.

- The 85th percentile of the parameter of interest is considered, taken from real data, while others are constant.

The fatigue and deformation lives were then estimated from the calculated asphalt and subgrade strains using equations (1) and (2). It is noted that, for a normal probability distribution, the 15th percentile is approximately equal to the mean minus one standard deviation. Similarly, the 85th percentile is approximately equal to the mean plus one standard deviation. As the lognormal distribution is a probability distribution whose logarithm has a normal distribution, the 15th and 85th percentiles can be calculated as above but by using instead the mean and standard deviation of the logarithms.

While percentiles from real data were used for Ta, Esb, Tsb, and Esg, for Ea a different procedure was employed. Corrections were made to each section's backanalysed stiffness value to account for the section's asphalt layer thickness variability (see Collop 2000). For the asphalt stiffness values, the 15th and 85th percentiles were calculated from the mean and standard deviation of the logarithms with the following procedure:

- Once the section's back-analysed asphalt stiffness mean $\left(\mu_{E_{F W n}}\right)$ and standard deviation $\left(\sigma_{E_{F W n}}\right)$ were calculated, Collop (2000) was used to predict the FWD stiffness modulus mean error and the FWD stiffness modulus standard deviation error. The errors are termed $\varepsilon_{\text {mean }}$ and $\varepsilon_{s d}$ here for simplicity. The true section's asphalt stiffness mean $(\bar{E})$ and standard deviation $\left(\sigma_{\Delta E}\right)$ were then calculated (i.e $\bar{E}=\mu_{E_{F W n}} * \varepsilon_{\text {mean }}$ and $\left.\sigma_{\Delta E}=\sigma_{E_{F W D}} * \varepsilon_{s d}\right)$.

- The mean of the logarithms of the individual (and corrected for asphalt thickness variability) asphalt stiffness values was calculated, which is $m=$ average $\left[\ln \left(E_{F W D_{i}} * \varepsilon_{\text {mean }}\right)\right]$, averaged over $\mathrm{n}$ number of data points, and where $E_{F W D_{i}}$ is the individual (uncorrected) asphalt stiffness value.

- The standard deviation of the logarithms of the individual asphalt stiffness values was calculated (and corrected for asphalt thickness variability), which is $s d=\operatorname{stdev}\left[\ln \left(E_{F W D_{i}}\right)\right] * \varepsilon_{\text {sdd }}$.

- The $15^{\text {th }}$ percentile was calculated as $e^{(m-s d)}$ and the $85^{\text {th }}$ percentile was calculated as $e^{(m+s d)}$.

The ratio of the calculated fatigue $\left(\mathrm{N}_{\mathrm{f}}\right)$ and deformation life $\left(\mathrm{N}_{\mathrm{d}}\right)$ over the corresponding base case was calculated for each scenario. The results of the analysis are shown in Figure 8 and Figure 9. 


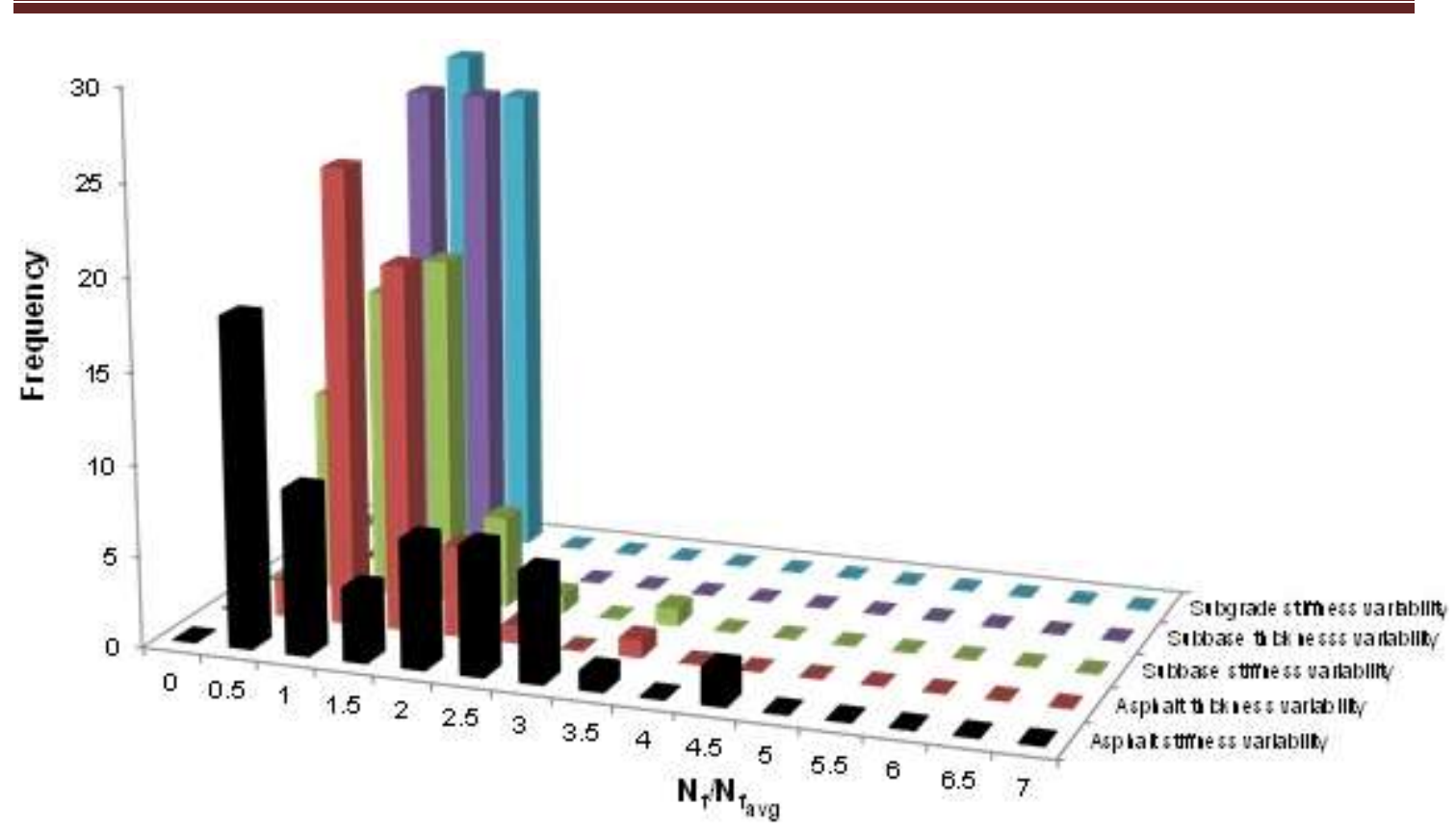

Figure 8. Estimated effect of variability of main design input variables on fatigue life

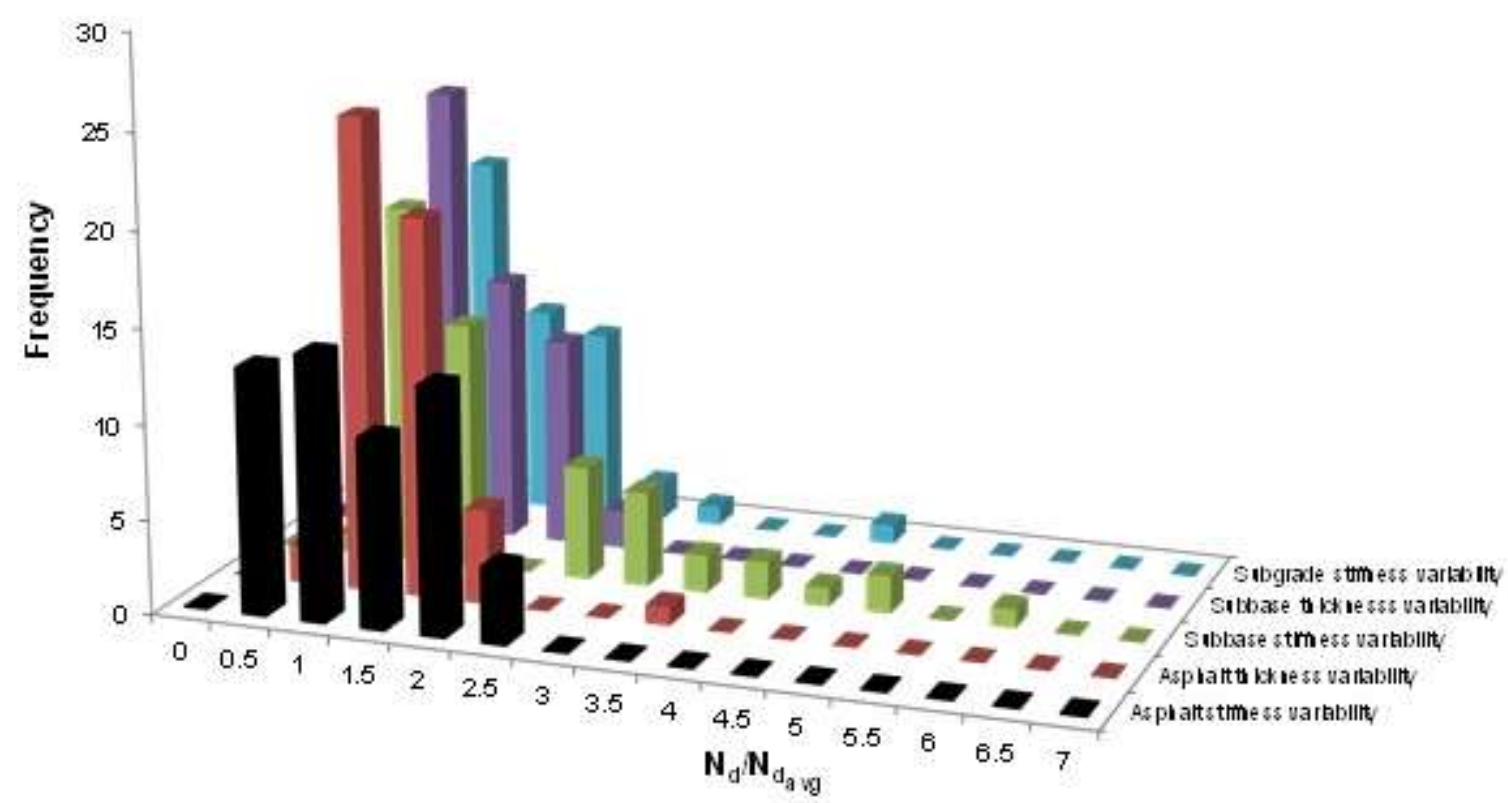

Figure 9. Estimated effect of variability of main design input variables on deformation life

The following observations can be made from the graphs above (i.e., by looking at the spread of the life ratio over the base scenario resulting from the $15^{\text {th }}$ and $85^{\text {th }}$ percentiles of the selected pavement input parameters):

- The parameters with the greatest influence on the variability of predicted fatigue performance are the asphalt stiffness modulus $\left(\mathrm{E}_{\mathrm{a}}\right)$ and thickness $\left(\mathrm{T}_{\mathrm{a}}\right)$.

- Fatigue life is affected by changes in the asphalt surface layer thickness $\left(T_{a}\right)$ while it is unaffected by changes in the granular subbase layer thickness $\left(\mathrm{T}_{\mathrm{sb}}\right)$.

- The parameters with the greatest influence on the variability of predicted deformation (rutting) performance are the granular subbase thickness $\left(\mathrm{T}_{\mathrm{sb}}\right)$, the asphalt thickness $\left(T_{a}\right)$, and the stiffness of the subgrade $\left(E_{s g}\right)$. 
- The observations above do not include any variation in traffic.

- The stiffness of the subbase $\left(\mathrm{E}_{\mathrm{sb}}\right)$ also appears to influence the variability of predicted deformation (rutting) performance. However, it is noted that the section's average backcalculated subbase stiffness is in most cases low (less than $150 \mathrm{MPa}$ ) and lower than the backcalculated subgrade modulus. For a typical flexible pavement with a well performing foundation, it is expected that the subbase stiffness is at least $150 \mathrm{MPa}$ and/or about 2 to 3 times the subgrade stiffness. In the very few cases where this condition is satisfied, the subbase stiffness has little influence on the variability of predicted deformation (rutting) performance.

- In connection with the previous observation, it is noted that the goodness of fit has been monitored but not included in the analysis.

- The probability distribution that best fits both fatigue and deformation lives is lognormal.

Combining the effects of all five parameters, the maximum range of $15^{\text {th }}$ and $85^{\text {th }}$ percentiles (as percentages of the mean) was found to be $64 \%$ to $558 \%$ for the fatigue life and $94 \%$ to $808 \%$ for the deformation life, see Table 2.

Table 2. Effect of each individual variable on $\mathrm{Nf}$ and $\mathrm{Nd}$

\begin{tabular}{|l|l|l|l|l|}
\hline Maximum \% mean & Nf-1SD & Nf+1SD & Nd-1SD & Nd+1SD \\
\hline Asphalt stiffness & 74 & 533 & 78 & 272 \\
\hline Asphalt thickness & 94 & 254 & 94 & 355 \\
\hline Subbase stiffness & 96 & 319 & 109 & 503 \\
\hline Subbase thickness & 106 & 115 & 96 & 209 \\
\hline Subgrade stiffness & 97 & 136 & 90 & 578 \\
\hline Combined effect & 64 & 558 & 94 & 808 \\
\hline
\end{tabular}

\section{CONCLUSIONS}

The research has confirmed that variability of the main pavement design input variables (asphalt modulus and thickness, subgrade modulus) - but excluding the variability of the traffic loading - affect the pavement performance. Variations of input design parameters have been discussed and quantified, as well as resulting variations of pavement performance (in terms of fatigue and deformation life). Variability has been described by statistical terms such as mean and standard deviation and by its probability density distribution.

This research has confirmed that the parameters with the greatest influence on the variability of predicted fatigue performance are the asphalt stiffness modulus and thickness. The parameters with the greatest influence on the variability of predicted deformation performance are the granular subbase thickness, the asphalt thickness and the subgrade stiffness. The probability distribution that best fits both fatigue and deformation lives was shown to be lognormal. Combining the effects of all the parameters, the maximum range of 15th and 85th percentiles (as percentages of the 
mean) was found to be $64 \%$ to $558 \%$ for the fatigue life and $94 \%$ to $808 \%$ for the deformation life.

Other important conclusions of the research study are:

Layer thickness variability

- The probability distribution for the layer thickness for the UK sites can be considered normal and the coefficient of variation is broadly similar to those reported in the American literature (e.g., average 10\% COV for the asphalt layer and $15 \% \mathrm{COV}$ for the subbase layer).

- The asphalt and the sub-base layer thicknesses can be considered uncorrelated.

Asphalt stiffness modulus variability

- In order for the FWD back-analysis to give reliable estimates of the in-situ asphalt stiffness modulus, it is essential to use accurate pavement layer thickness information.

- The average error due to random measurement deflection error was less than $1 \%$ on back-analysed asphalt stiffness and close to $0 \%$ on back-analysed subgrade stiffness.

- With both the effect of random error in the deflection measurement and the effect of variation of layer thickness included in the analysis, a relationship was proposed to calculate the adjusted standard deviation.

- Based on the plots of ITSM tests on the M01 site, the coefficient of variation of the asphalt layer stiffness modulus appeared, on average, to range from $20 \%$ to $40 \%$.

- A lognormal probability distribution was found representative of the asphalt layer stiffness modulus.

\section{Subgrade stiffness modulus variability}

- Based on a 'cusum' analysis on the available sites, the coefficient of variation of the back-analysed subgrade stiffness modulus for all sites varied from a minimum of $8 \%$ to a maximum of $129 \%$, with an average value of $56 \%$. The high uncertainty in the data is probably due to the small sample size derived from the cusum analysis.

- A lognormal probability distribution was found in most cases to be representative of the subgrade stiffness.

\section{FURTHER WORK}

The authors recommend extending the study to see if current UK pavement design methods (HD25/IAN73 and HD 26) are adequate given the observed variability of the different parameters and the effect of this on predicted design life.

To complete the research other important design properties should be considered such as traffic, asphalt bitumen content and compaction (i.e., air voids percent) to name the most critical ones. The research could also be extended to hydraulically bound layers, i.e. flexible composite pavements, and possibly to surface damage (fretting, potholes) as predictive methods become available. 


\section{REFERENCES}

Aguiar-Moya, J.P., Banerjee, A., and Prozzi, J.A. (2009) "Sensitivity Analysis of the M-E PDG Using Measured Probability Distributions of Pavement Layer Thickness", 88th Transportation Research Board Annual Meeting.

American Association of State Highway and Transportation Officials (1993) "AASHTO Guide for Design of Pavement Structures", Washington D.C.

American Association of State Highway and Transportation Officials (2008) "Mechanistic-Empirical Pavement Design Guide", Washington D.C.

American Association of State Highway and Transportation Officials (1985) "Proposed AASHTO Guide for Design of Pavement Structures, NCHRP Project 207/24, Washington, DC, USA.

Collop, A.C. (2000) "The Effect of Asphalt Layer Thickness Variations on Pavement Evaluation Using the Falling Weight Deflectometer", School of Civil Engineering, Vol.1 (4), pp247-263.

Darter, M., Hudson, W. R., and Brown, J. L. (1973) "Statistical variations of flexible pavement properties and their consideration in design", Proceedings, Association of Asphalt Technologists, Vol.42, pp589-613.

George, K.P. and Husain, S. (1986) "Thickness design for flexible pavement: a probabilistic approach", Transportation Research Record, Vol.1095, pp26-36.

Highways Agency, Design Manual for Roads and Bridges (DMRB), "HD 26 Pavement Design".

Highways Agency, Design Manual for Roads and Bridges (DMRB), "HD 29 Data for Pavement Assessment".

Irwin, L.H., Yang, W.S., and Stubstad, R.N. (1989) "Deflection Reading Accuracy and Layer Thickness Accuracy in Backcalculation of Pavement Layer Moduli", American Society for Testing and Materials.

Jiménez, L.A. and Mrawira, D. (2012) "Bayesian Regression in Pavement Deterioration Modeling: Revisiting the AASHO Road Test Rut Depth Model", Infraestructura Vial $\mathrm{Nr} 25$.

Kim, H. B. and Buch, N. (2003) "Reliability-based pavement design model accounting for inherent variability of design parameters", 82nd Transportation Research Board Annual Meeting.

Noureldin, A.S., Sharaf, E., Arafah, A., and Al-Sugair, F. (1994) "Estimation of Standard Deviation of Predicted Performance of Flexible Pavements using AASHTO Model", Transportation Research Record, Vol.1449, pp46-56.

Powell, W.D., Potter, J.F.,Mayhew, H.C., and Nunn, M.E. (1984) "The structural design of bituminous roads", Transport and Road Research Laboratory, LR 1132, UK.

Prozzi, J.A. and Guo, R. (2007) "Reliability-based approach for using LTPP and APT test results for estimating fatigue performance", 86th Transportation Research Board Annual Meeting.

Tighe, S. (2001) "Guidelines for probabilistic pavement life cycle cost analysis", TRB, Vol.1769, pp28-38. 
Tighe, S., He, Z., and Haas, R. (2001) "Environmental deterioration model for flexible pavement design: an Ontario example", 80th Transportation Research Board Annual Meeting.

Timm, D.H., Newcomb, D.E., and Galambos, T.V. (2000) "Incorporation of reliability into Mechanistic-Empirical pavement design", Transportation Research Record, Vol.1730, pp73-80.

TRB's Transportation Research Circular E-C118 (2007) "Pavement Lessons Learned from the AASHO Road Test and Performance of the Interstate Highway System".

Ullidtz, P. (1987) "Pavement analysis", Elsevier.

Zollinger, D.G. and McCullough, B.F. (1994) "Development of Weibull Reliability factors and analysis for calibration of pavement Design Models Using Filed Data", Transportation Research Record, Vol.1449, pp18-25. 